\title{
APLIKASI EDUKASI “MUSIC TRADITIONAL ARCADE” BERBASIS ANDROID
}

\author{
David; Andiny Rucitra; Fibriyenti; Anthonio \\ Jurusan Teknik Informatika, School of Computer Science, BINUS University \\ Jln. K.H. Syahdan No. 9, Palmerah, Jakarta Barat 11480 \\ david_angkasa06@yahoo.co.uk
}

\begin{abstract}
The purpose of this study is to assist the government in introducing traditional music instruments in Indonesia to the community, especially teenagers aged from 16-20 years. Given increasingly in modern era makes people start to forget traditional music instruments and prefers modern music instruments. The method used in this research is literature study, observation, application design, and application testing that has been made. Result obtained from this study is an application that can meet the objectives of the study. The conclusion of this study is that the application gave elements and information about some traditional music instruments in interesting ways through mobile app game followed with attractive appearance and could be one way of helping the government to preserve traditional music instruments and provide insight into knowledge through the history of the instrument.
\end{abstract}

Keywords: games, android, traditional music instruments, teens, smartphone

\begin{abstract}
ABSTRAK
Tujuan dari penelitian ini adalah untuk membantu pemerintah dalam memperkenalkan kembali kepada masyarakat terutama remaja yang berusia dari 16 - 20 tahun tentang beberapa alat musik tradisional yang ada di Indonesia. Mengingat, zaman yang makin modern membuat masyarakat mulai melupakan alat musik tradisional dan lebih memilih alat musik moderen. Metode penelitian yang digunakan pada penelitian ini adalah studi literatur, observasi, perancangan aplikasi, dan uji coba aplikasi yang telah dibuat. Hasil yang dicapai dari penelitian ini adalah sebuah aplikasi yang dapat memenuhi tujuan dari penelitian. Simpulan yang didapat dari penelitian ini adalah aplikasi yang dibuat telah memberikan unsur-unsur dan informasi mengenai beberapa alat musik tradisional dengan cara yang menarik, yaitu melalui aplikasi mobile game diikuti dengan tampilan yang menarik serta dapat menjadi salah satu cara membantu pemerintah untuk melestarikan alat musik tradisional dan memberikan wawasan pengetahuan melalui sejarah dari alat musik tersebut.
\end{abstract}

Kata kunci: game, android, alat musik tradisional, remaja, smartphone 


\section{PENDAHULUAN}

Indonesia memiliki banyak sekali kebudayaan yang dapat dibanggakan, salah satunya adalah alat musik tradisional. Alat musik merupakan suatu instrumen yang dibuat atau dimodifikasi dengan tujuan menghasilkan suara atau bunyi yang menghasilkan sebuah irama. Setiap daerah di Indonesia pasti memiliki alat musik tradisional. Salah satu kegunaan alat music tradisional selain untuk menghibur bisa juga digunakan untuk keperluan upacara adat. Seiring perkembangan zaman, kepedulian pelestarian kebudayaan nasional, khususnya alat musik tradisional, menjadi sangat minim. Banyak orang yang lebih memilih memainkan alat musik modern daripada memainkan alat musik tradisional. Sebagai contoh, kurangnya pengenalan dan sosialisasi akan budaya Indonesia di masyarakat merupakan salah satu faktor penting mengapa minat masyarakat menjadi kurang terhadap alat musik tradisional. Dengan minat yang kurang tersebut, hendaknya masyarakat Indonesia berinisiatif untuk mulai melestarikan kebudayaan sendiri. Banyak sekali wisatawan luar negeri yang memberikan apresiasi tinggi terhadap kebudayaan Indonesia dibandingkan dengan masyarakat Indonesia sendiri (Aminuddin, 2009). Alat musik tradisional adalah warisan budaya yang harus dipertahankan dan diwariskan kepada generasi penerus bangsa.

Minimnya kepedulian masyarakat Indonesia akan musik tradisional disebabkan oleh beberapa faktor, seperti kurangnya pengenalan dan pemahaman tentang alat musik tradisional sejak dini, kurangnya ketersediaan dan minimnya tenaga ahli, remaja sekarang menganggap kesenian musik tradisional tidak mengikuti perkembangan zaman dan sudah tertinggal jauh dengan alat musik modern yang sudah mulai merebut perhatian masyarakat Indonesia khususnya pada tingkatan remaja. Melihat masalah ini, penelitian mencoba untuk membantu pemerintah dalam melestarikan kebudayaan khususnya bagian alat musik tradisional dengan membuat sebuah aplikasi game berbasis Android yang diharapkan dapat membantu menanamkan pengetahuan tentang keanekaragaman alat musik yang ada di Indonesia kepada para remaja (Adams, 2010; Bangkong, 2009).

Mengingat remaja zaman sekarang lebih banyak menghabiskan waktunya dengan memilih bermain game dibandingkan belajar, wawasan mereka tentang kebudayaan negeri mereka sendiri menjadi sempit (Priawan, 2013). Hampir sebagian besar remaja tidak mengetahui budaya bangsa mereka sendiri. Budaya bangsa Indonesia yang beraneka ragam merupakan jati diri yang dimiliki oleh bangsa Indonesia, sehingga penting bagi remaja untuk mempertahankannya. Dengan alasan itu, penelitian membuat suatu game edukasi untuk mendidik para remaja agar lebih memerhatikan kebudayaan bangsa (Utama, 2011).

Permasalahan yang diidentifikasi dalam penelitian ini adalah membuat masyarakat tertarik terhadap budaya tanah air khususnya alat musik tradisional; bagaimana cara melestarikan alat musik tradisional; dan menambah pengetahuan tentang alat musik tradisional. Sementara tujuan yang ingin dicapai penelitian, yaitu: melestarikan budaya alat musik tradisional; memperkenalkan beberapa macam alat musik tradisional yang berasal dari Indonesia dengan cara yang menarik; menghasilkan suatu aplikasi mobile game yang dapat memberikan wawasan pengetahuan kepada remaja tentang alat musik tradisional. Lebih lanjut, manfaat dari pembuatan aplikasi ini menambah wawasan budaya alat musik tradisional pada remaja; memupuk rasa cinta tanah air dengan cara melestarikan alat musik tradisional Indonesia; remaja menjadi tertarik dengan budaya alat musik tradisional karena disajikan secara menarik melalui game; remaja dapat mengenal alat musik tradisional melalui game "Music Traditional Arcade". 


\section{METODE}

Penelitian menggunakan model waterfall sebagai metodologi penelitian yang digunakan untuk merancang aplikasi ini (Shneiderman \& Plaisant, 2010; Whitten \& Bentley, 2007; Zechner, 2011). Model penelitian ini memiliki beberapa tahap, yaitu: requirements definition, system and software design, implementation and unit testing, integration and system testing, dan operation and maintenance. Sistem yang dirancang dibagi menjadi beberapa proses seperti pada Gambar 1.

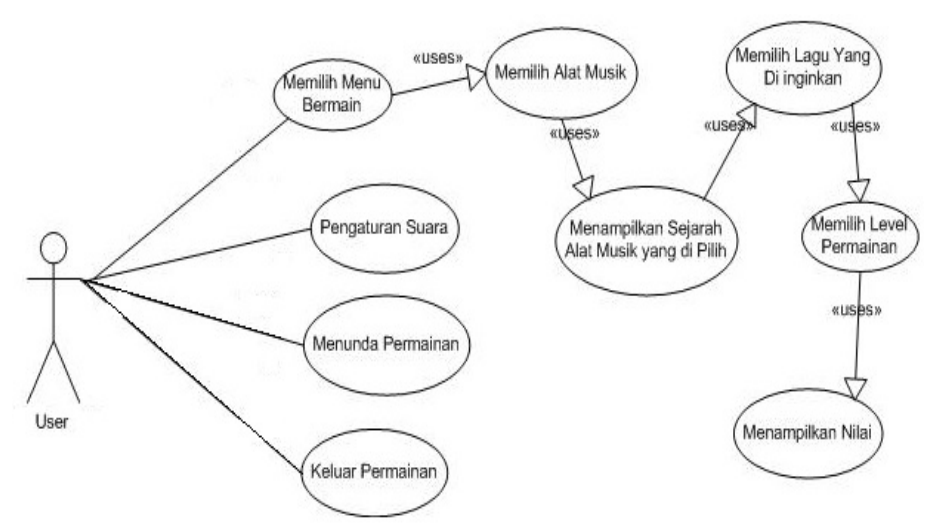

Gambar 1 Main Use Case Alat Musik Tradisional

Berikut ini menunjukkan objek-objek yang dibutuhkan dalam aplikasi.

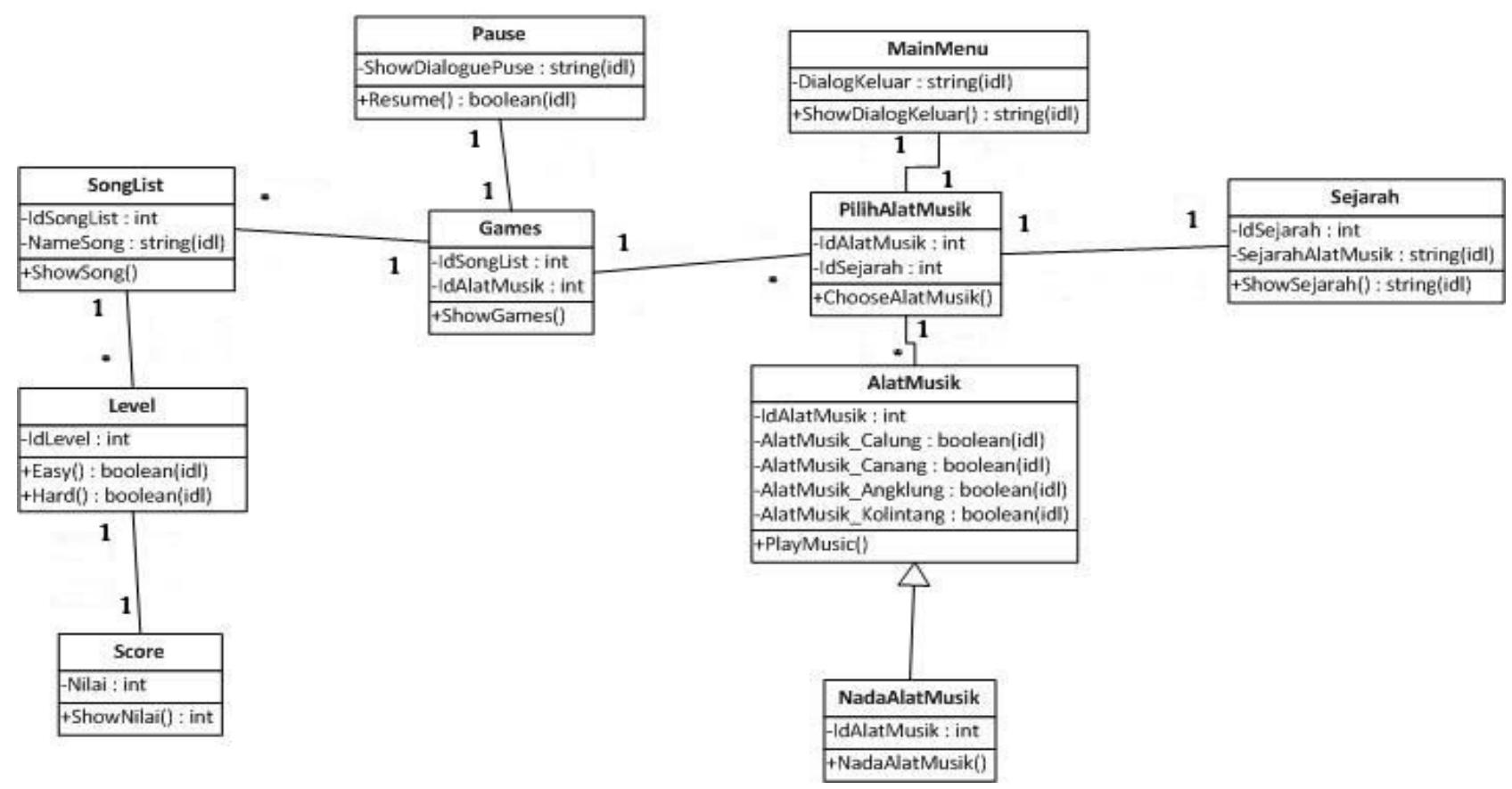

Gambar 2 Class Diagram 
Gambar 3, Gambar 4, dan Gambar 5 memperlihatkan alur proses yang dilakukan untuk aplikasi yang akan dibuat, sehingga semua proses yang dibuat dapat dilaksanakan dengan baik.

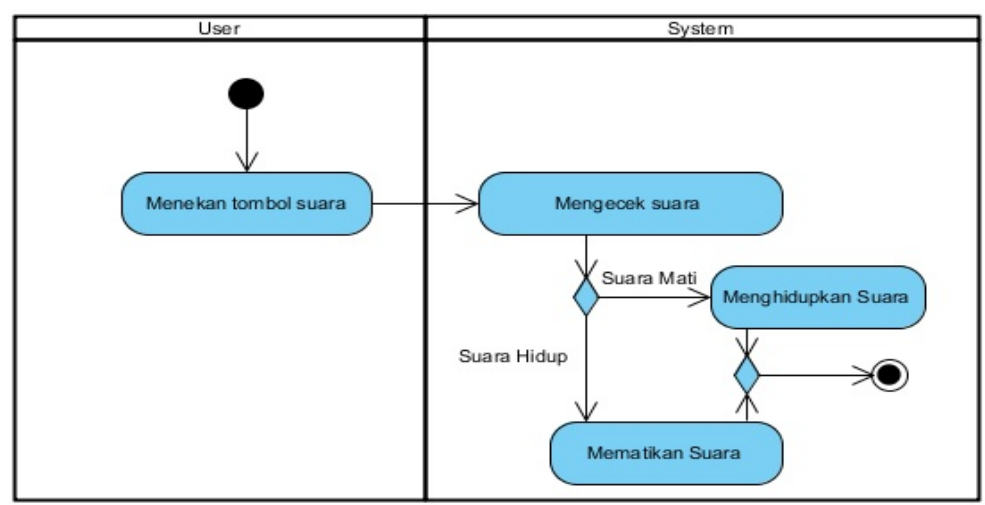

Gambar 3 Activity Diagram Setting Suara

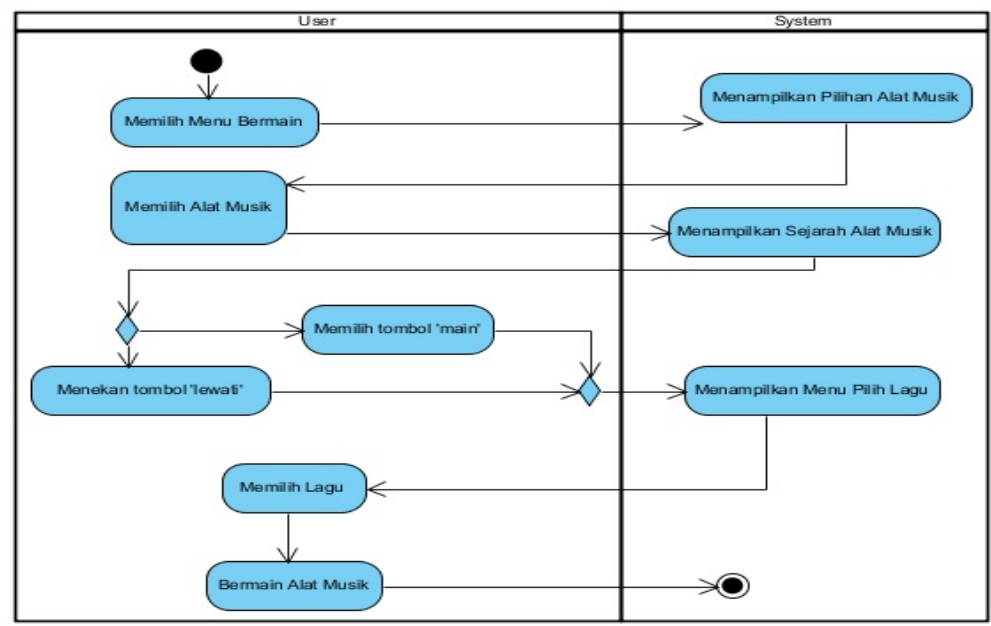

Gambar 4 Activity Diagram Pilih Menu Bermain

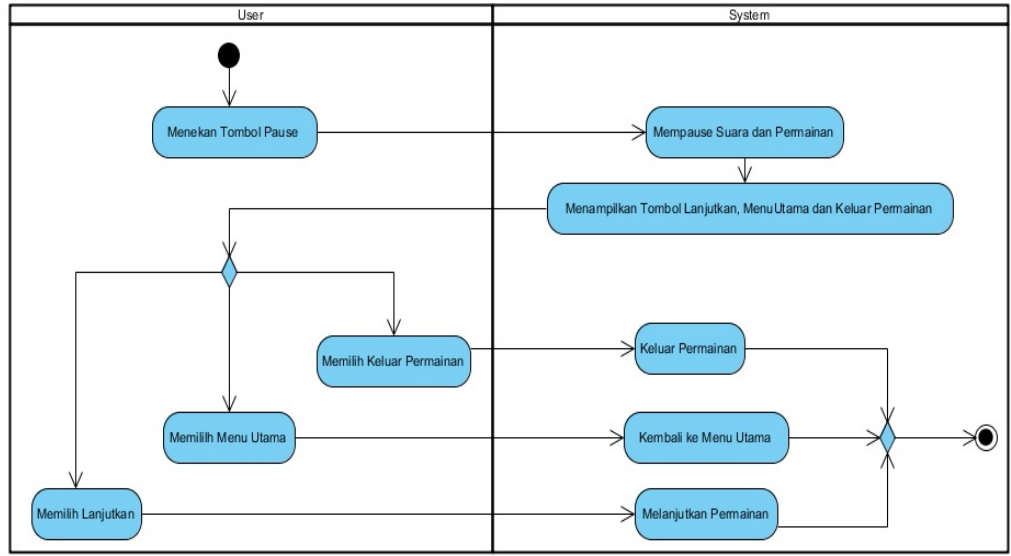

Gambar 5 Activity Diagram Pilih Menu Pause 


\section{HASIL DAN PEMBAHASAN}

Kuesioner disebarkan kepada 32 user yang mencoba aplikasi Alat Musik Tradisional agar mendapat evaluasi mengenai game yang telah dibuat. Tampilan aplikasi game "Alat Musik Tradisional” terdapat pada halaman Lampiran. Berikut ini adalah hasil yang didapat dari 9 pertanyaan.

Pertanyaan pertama, setelah memainkan game "Alat Musik Tradisional”, menurut Anda apakah game ini membuat anda tertarik dengan budaya alat musik tradisional? (a) sangat tertarik, (b) tertarik, (c) kurang tertarik, (d) tidak tertarik. Tabel 1 yang menampilkan tentang hasil jawaban kuesioner pada pertanyaan nomor 1 .

Tabel 1 Hasil jawaban kuesioner pada pertanyaan nomor 1

\begin{tabular}{rlcc}
\hline No & & Jumlah & $\mathbf{\%}$ \\
\hline 1. & Sangat Tertarik & 13 & 41 \\
2. & Tertarik & 12 & 38 \\
3. & Kurang Tertarik & 6 & 19 \\
4. & Tidak Tertarik & 1 & 3 \\
\hline & Jumlah & 32 & \\
\hline
\end{tabular}

Pertanyaan kedua, apakah tampilan UI pada game ini sudah menarik? (a) menarik, (b) kurang menarik. Tabel 2 yang menampilkan tentang hasil jawaban kuesioner pada pertanyaan nomor 2 .

Tabel 2 Hasil jawaban kuesioner pada pertanyaan nomor 2

\begin{tabular}{clcc}
\hline No & & Jumlah & \% \\
\hline 1. & Menarik & 27 & 84 \\
2. & Kurang Menarik & 5 & 16 \\
\hline & Jumlah & 32 & \\
\hline
\end{tabular}

Pertanyaan ketiga, seberapa banyak pengetahuan yang didapat setelah bermain game ini? (a) sangat banyak, (b) banyak, (c) cukup banyak, (d) tidak banyak. Tabel 3 menampilkan hasil jawaban kuesioner pada pertanyaan nomor 3.

Tabel 3 Hasil jawaban kuesioner pada pertanyaan nomor 3

\begin{tabular}{clcc}
\hline No & & Jumlah & \% \\
\hline 1. & Sangat Banyak & 9 & 28 \\
2. & Banyak & 15 & 47 \\
3. & Cukup Banyak & 7 & 22 \\
4. & Tidak Banyak & 1 & 3 \\
\hline & Jumlah & 32 & \\
\hline
\end{tabular}


Pertanyaan keempat, seberapa cepat anda terbiasa dengan navigasi game ini? (a) sangat cepat, (b) cepat, (c) cukup cepat, (d) tidak cepat. Tabel 4 menampilkan tentang hasil jawaban kuesioner pada pertanyaan nomor 4.

Tabel 4 Hasil jawaban kuesioner pada pertanyaan nomor 4

\begin{tabular}{clcc}
\hline No & & Jumlah & \% \\
\hline 1. & Sangat Cepat & 9 & 28 \\
2. & Cepat & 12 & 38 \\
3. & Cukup Cepat & 9 & 28 \\
4. & Tidak Cepat & 2 & 6 \\
\hline & Jumlah & 32 & \\
\hline
\end{tabular}

Pertanyaan kelima, setelah menggunakan aplikasi ini, apakah Anda mengerti cara menggunakan "Alat Musik Tradisional”? (a) mengerti, (b) cukup mengerti, (c) tidak mengerti. Tabel 5 menampilkan tentang hasil jawaban kuesioner pada pertanyaan nomor 5.

Tabel 5 Hasil jawaban kuesioner pada pertanyaan nomor 5

\begin{tabular}{clcc}
\hline No & & Jumlah & \% \\
\hline 1. & Mengerti & 16 & 50 \\
2. & Cukup Mengerti & 13 & 41 \\
3. & Tidak Mengerti & 3 & 9 \\
\hline \multicolumn{4}{c}{ Jumlah } \\
\hline
\end{tabular}

Pertanyaan keenam, apakah Anda pernah mengalami gangguan pada saat memainkan game ini? (a) pernah, (b) tidak pernah. Tabel 6 menampilkan tentang hasil jawaban kuesioner pada pertanyaan nomor 6 .

Tabel 6 Hasil jawaban kuesioner pada pertanyaan nomor 6

\begin{tabular}{clcc}
\hline No & & Jumlah & \% \\
\hline 1. & Pernah & 12 & 38 \\
2. & Tidak Pernah & 20 & 63 \\
\hline & Jumlah & 32 & \\
\hline
\end{tabular}

Pertanyaan ketujuh, jika pernah, gangguan apa yang terjadi? (a) crash game, (b) not responding, (c) others. Tabel 7 menampilkan tentang hasil jawaban kuesioner pada pertanyaan nomor 7 .

Tabel 7 Hasil jawaban kuesioner pada pertanyaan nomor 7

\begin{tabular}{clcc}
\hline No & & Jumlah & \% \\
\hline 1. & Crash Game & 4 & 31 \\
2. & Not Responding & 8 & 62 \\
3. & Others & 1 & 8 \\
\hline \multicolumn{2}{c}{ Jumlah } & 13 & \\
\hline
\end{tabular}


Pertanyaan kedelapan, apakah game ini menjadi salah satu cara untuk melestarikan "Alat Musik Tradisional"? (a) ya, (b) tidak. Tabel 8 menampilkan tentang hasil jawaban kuesioner pada pertanyaan nomor 8.

Tabel 8 Hasil jawaban kuesioner pada pertanyaan nomor 8

\begin{tabular}{clcc}
\hline No & & Jumlah & \% \\
\hline 1. & Ya & 23 & 72 \\
2. & Tidak & 9 & 28 \\
\hline \multicolumn{4}{r}{ Jumlah } \\
\hline
\end{tabular}

Pertanyaan kesembilan, apakah ada saran atau masukan untuk pengembangan terhadap aplikasi game ini? Tabel 9 menampilkan tentang hasil jawaban kuesioner pada pertanyaan nomor 9.

Tabel 9 Hasil jawaban kuesioner pada pertanyaan nomor 9

\begin{tabular}{cl}
\hline No & \multicolumn{1}{c}{ Saran } \\
\hline 1. & $\begin{array}{l}\text { Ayo dikembakan lagi gamenya, bisa sebagai sarana pelestarian budaya alat } \\
\text { musik tradisional }\end{array}$ \\
2. & Luar Biasa Kreatif \\
3. & Game yang luar biasa. gara-gara game ini saya jadi tau sejarah tuh alat musik. \\
4. & $\begin{array}{l}\text { Sarannya kalau bisa ditambah alat musiknya jadi kita dapat tahu alat-alat musik } \\
\text { tradisional lainnya, karena pada zaman sekarang ini anak-anak sudah jarang } \\
\text { bermain alat musik tradisional jadi dengan adanya game ini membuat anak- } \\
\\
\text { anak lebih tertarik untuk memainkan game alat musik tradisional. }\end{array}$ \\
\hline
\end{tabular}

Dari hasil kuesioner, dapat dilihat bahwa hasil yang dicapai memiliki tingkat kepuasan yang tinggi mengenai hasil dari tampilan dan kegunaan dari aplikasi yang sudah dirancang. Akan tetapi, terdapat beberapa kesalahan pada tampilan. Terdapat beberapa kesulitan dalam berinteraksi. Dari kesalahan yang ada tidak menjadi masalah yang berarti sehingga aplikasi yang dihasilkan dapat bermanfaat dan berguna untuk pembelajaran alat musik.

\section{SIMPULAN}

Simpulan yang diperoleh dari hasil analisis, perancangan, implementasi, serta evaluasi dari game Music Traditional Arcade ini adalah pertama, game ini membuat masyarakat menjadi tertarik dengan alat musik tradisional yang ada di Indonesia. Kedua, target utama dari game Musik Tradisional Arcade adalah remaja yang berusia 16-20 tahun. Ketiga, game Musik Tradisional Arcade merupakan game yang menambah pengetahuan. Keempat, game Musik Tradisional Arcade memiliki tampilan yang menarik. Kelima, pembuatan aplikasi game ini dapat membantu melestarikan budaya alat musik tradisional. 


\section{DAFTAR PUSTAKA}

Adams, E. (2010). Fundamentals of Game Design. $2^{\text {nd }}$ Ed. USA: Pearson Education.

Aminuddin. (2009). Apresiasi Karya Seni Musik Daerah Nusantara. Jakarta: Sinar Baru.

Bangkong, A. (2009). Pendekatan Belajar Sambil Bermain. Seminar Penyelidikan Tindakan IPG KBL Tahun 2012, 1-15.

Priawan, M. Y. (2013). Teknologi, Smartphone, dan Android. Jurnal Ilmiah Teknologi Pendidikan Unnes.

Shneiderman, B., \& Plaisant, C. (2010). Designing The User Interface : Strategies for Effective Human-Computer Interaction, $5^{\text {th }}$ edition. United States of America: Pearson Education.

Utama, P. S. (2011, 6 Juni). Nielsen: Android Paling Banyak Mengkonsumsi Data Mobile. Diakses 6 April 2014 dari http://teknojurnal.com/nielsen-android-paling-banyak-mengkonsumsi-datamobile/

Whitten, J. L., \& Bentley, L.D. (2007). System Analysis and Design Methods. $7^{\text {th }}$ edition. New York: McGraw Hill.]

Zechner, M. (2011). Beginning Android Games. $1^{\text {st }}$ Ed. New York: Apress. 


\section{LAMPIRAN}

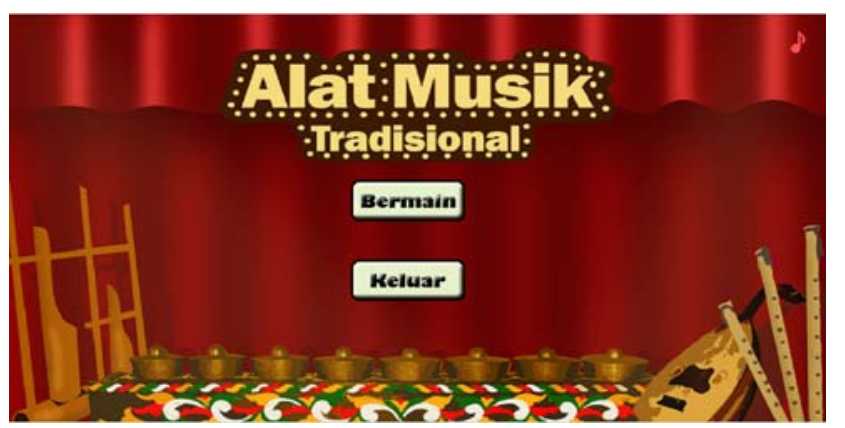

Gambar 6 Layar Menu Utama

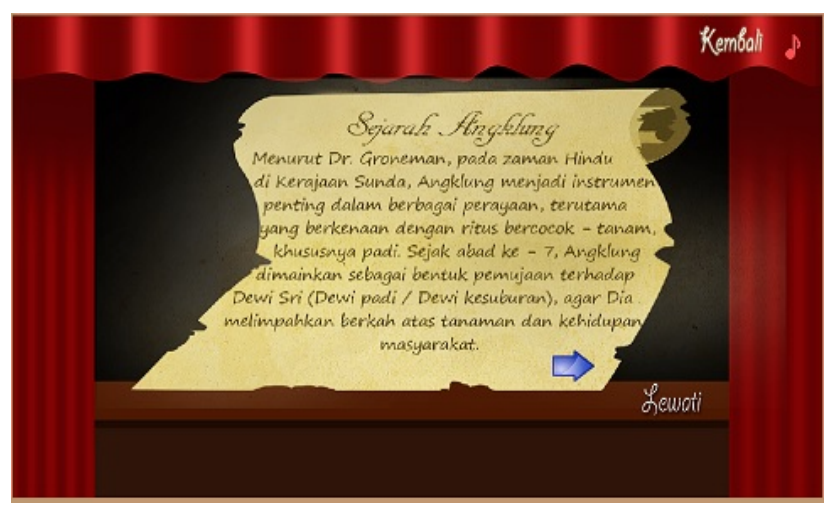

Gambar 8 Layar Sejarah

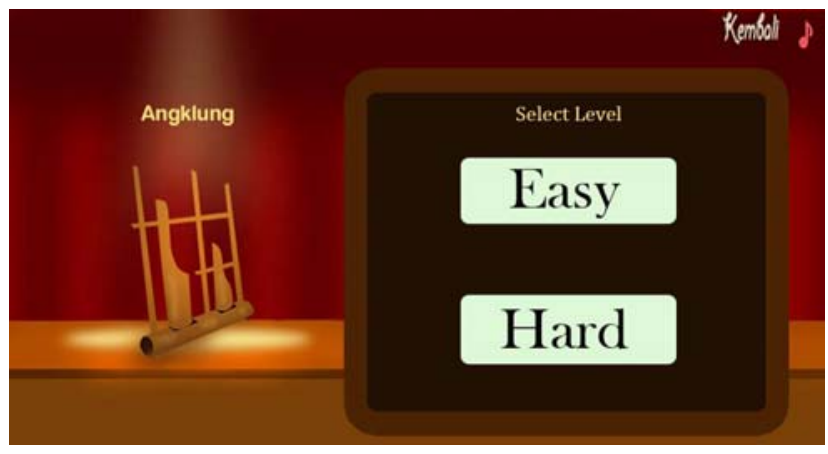

Gambar 10 Layar Pilih Level

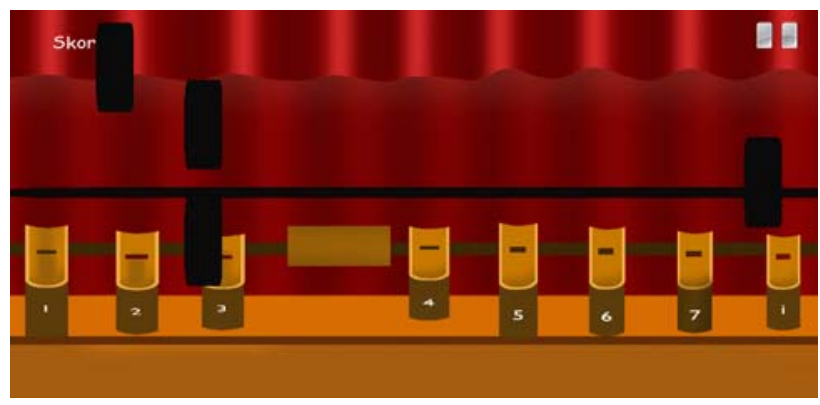

Gambar 12 Layar Game Calung

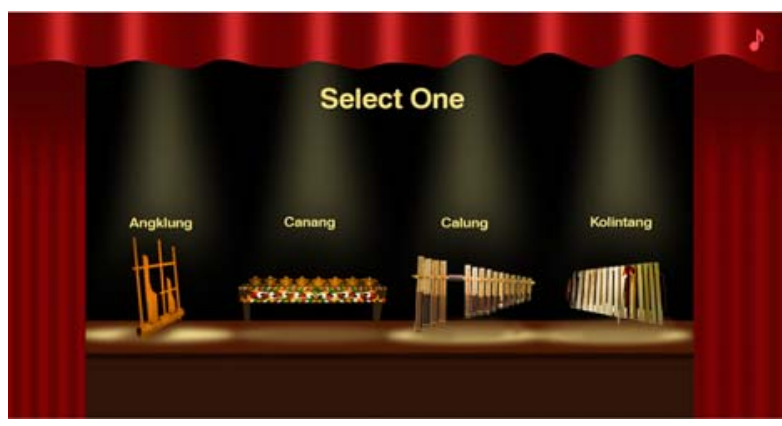

Gambar 7 Layar Pilih Alat Musik

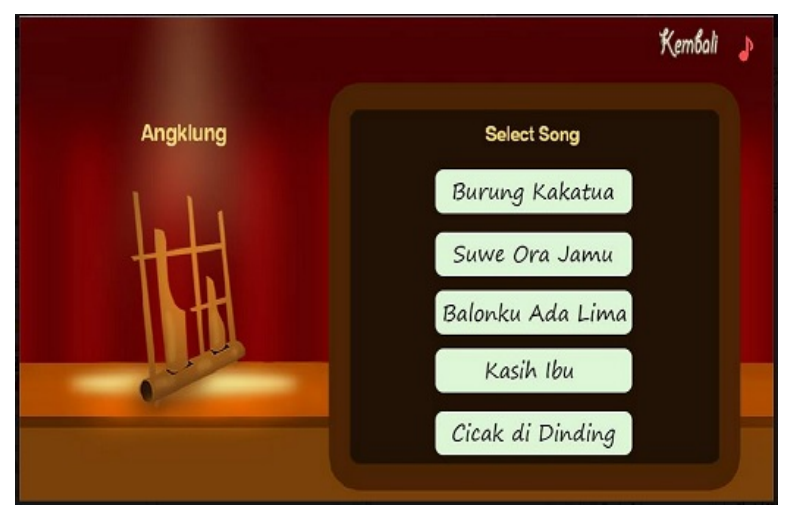

Gambar 9 Layar Pilih Lagu

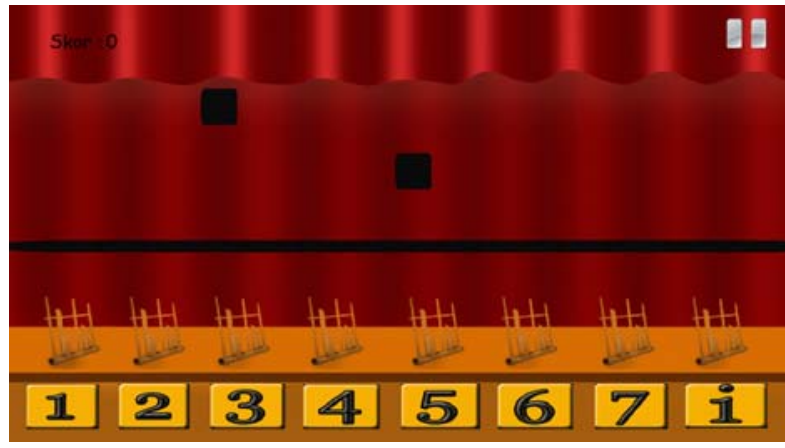

Gambar 11 Layar Game Angklung

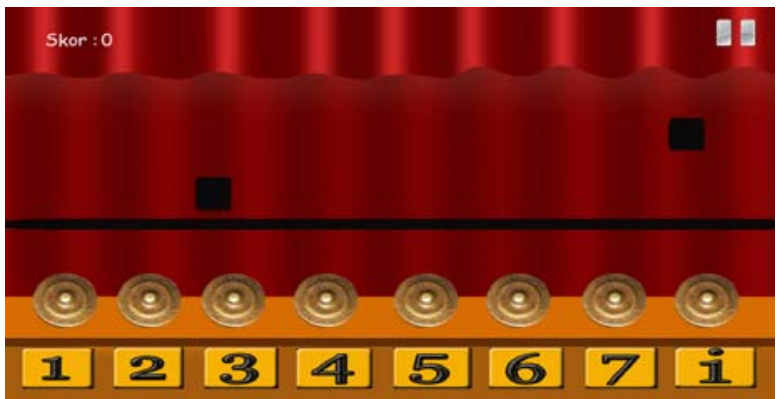

Gambar 13 Layar Game Canang 


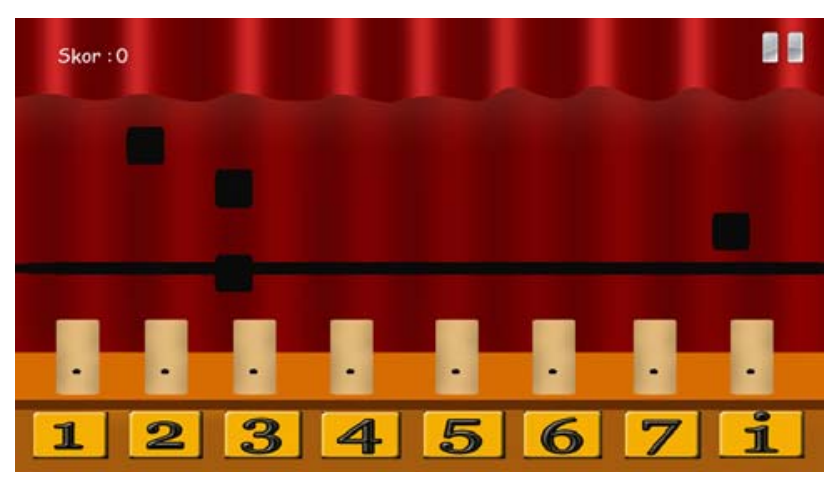

Gambar 14 Layar Game Kolintang

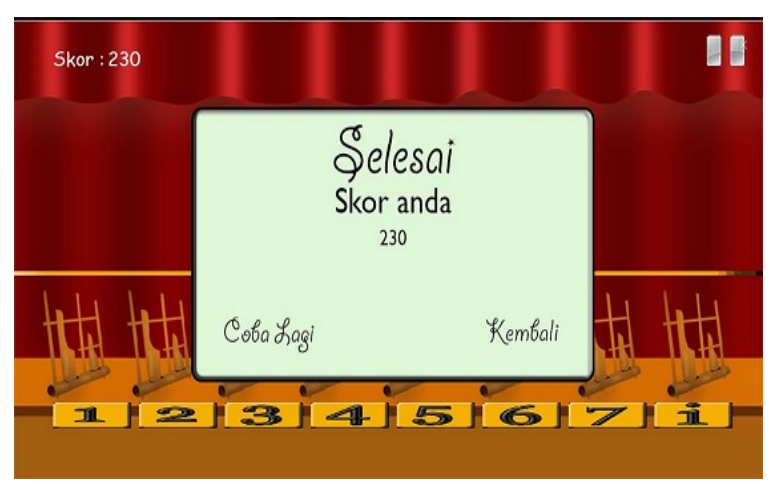

Gambar 15 Layar Score 